\title{
Characterization Methodology for Anode Starvation in HT-PEM Fuel Cells
}

\author{
Khrystyna Yezerska, ${ }^{1,2 \star}$ Anastasia Dushina ${ }^{1}$, Fang Liu ${ }^{1}$, Maren Rastedt ${ }^{1}$, Peter \\ Wagner ${ }^{1}$, Alexander Dyck ${ }^{1}$, Michael Wark ${ }^{2}$ \\ ${ }^{1}$ DLR Institute of Networked Energy Systems, 26129 Oldenburg, Germany \\ ${ }^{2}$ Institute of Chemistry, Carl von Ossietzky University, 26129 Oldenburg, Germany \\ *Corresponding author, email: khrystyna.yezerska@dlr.de Tel.: +49 44199906346
}

\begin{abstract}
Degradation caused by fuel starvation may be an important reason for limited fuel cell lifetimes. In this work, we present an analytical characterization of the high temperature polymer exchange membrane fuel cell (HT-PEM FC) behavior under cycled anode starvation and subsequent regeneration conditions to investigate the impact of degradation due to $\mathrm{H}_{2}$ starvation. Two membrane electrode assemblies (MEAs) with an active area of $21 \mathrm{~cm}^{2}$ were operated of up to 550 minutes, which included up to 14 starvation / regeneration cycles. Overall cell voltage as well as current density distribution $\left(\mathrm{S}^{++}\right.$unit) were measured simultaneously each minute during FC operation. The cyclicity of experiments was used to check the long term durability of the HT-PEM FC. After FC operation, micro-computed tomography $(\mu-\mathrm{CT})$ was applied to evaluate the influence of starvation on anode and cathode catalyst layer thicknesses.
\end{abstract}

During starvation, cell voltage and current density distribution over the active area of the MEA significantly differed from nominal conditions. A significant drop in cell voltage from 0.6 to $0.1 \mathrm{~V}$ occured after approx. 20 minutes for the first starvation step, and after 10 minutes for all subsequent starvation steps. By contrast, the voltage response is immediately stable at $0.6 \mathrm{~V}$ during every regeneration step. During each starvation, the local current density reached up to $0.3 \mathrm{~A} \cdot$ point $^{-1}$ at the area near the gas inlet $\left(9 \mathrm{~cm}^{2}\right)$ while near the outlet it drops to $0.01 \mathrm{~A} \cdot$ point $^{-1}$. The deviation from a balanced current density distribution occurred after 10 minutes for the first starvation step, and after ca. 2 minutes for the subsequent starvation steps. Hence, compared to the voltage drop, the deviation from a balanced current density distribution always starts earlier. This indicates that the local current density distribution is more sensitive to local changes in the MEA than overal cell voltage drop. This finding may help to prevent undesirable influences of the starvation process.

The $\mu$-CT images showed that $\mathrm{H}_{2}$ starvation lead to thickness decrease of ca. 20$30 \%$ in both anode and cathode catalyst layers compared to a fresh MEA. Despite of the 14 starvation steps and the thinning of the catalyst layers the MEA presents stable cell voltage during regeneration.

\section{Key words:}

HT-PEM FC, hydrogen starvation; regeneration; voltage; current density distribution; $\mu-\mathrm{CT}$. 


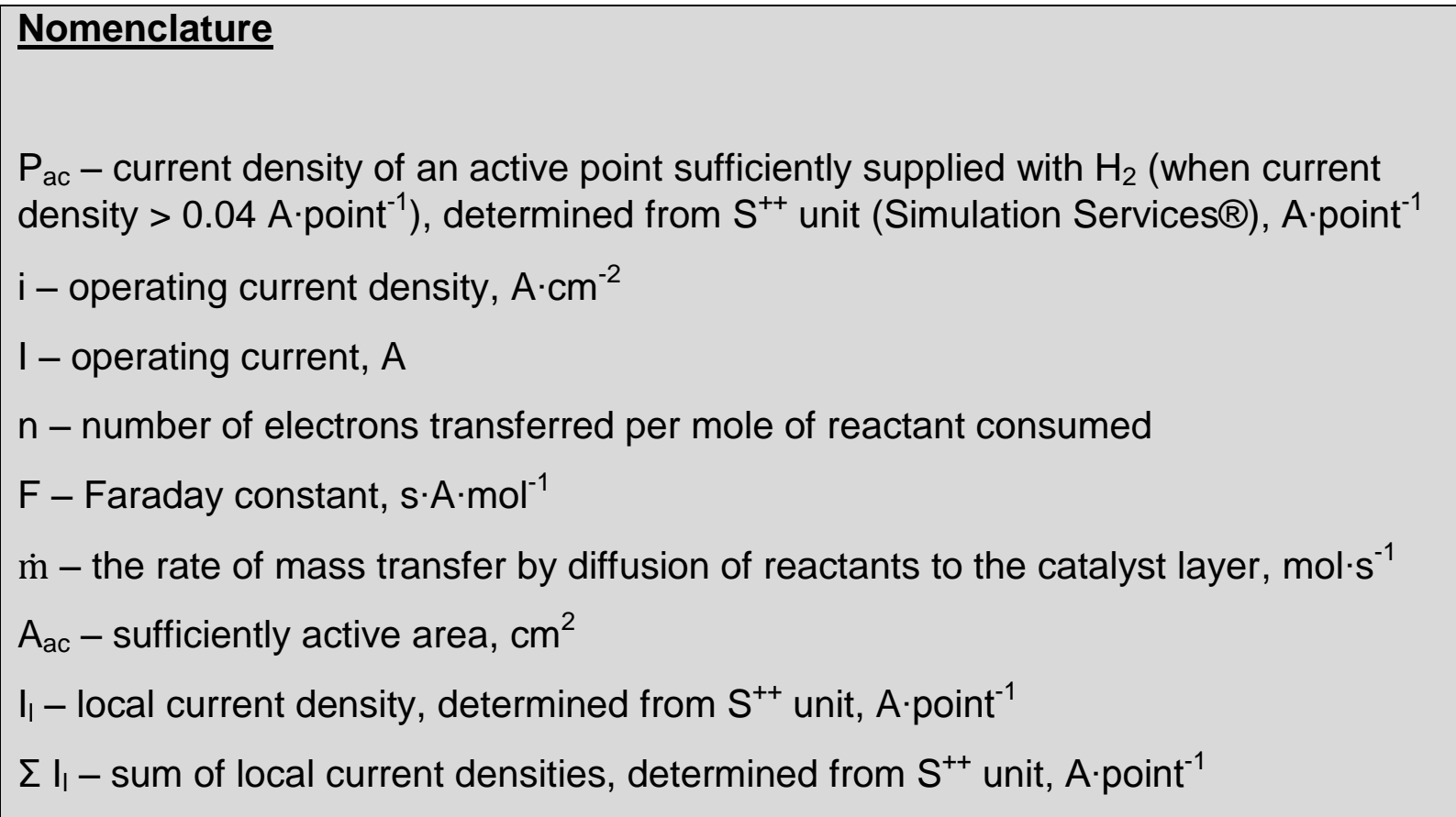

\section{Introduction}

High temperature polymer exchange membrane fuel cells (HT-PEM FC) have entered the market in the last decade [1]. This type of FC is considered as a clean and efficient power source for portable and stationary applications such as combined heat and power (CHP) application, stand-alone power, backup power and uninterrupted power supply (UPS) [2-6]. In HT-PEM FC a polybenzimidazole (PBI) membrane doped with phosphoric acid is used. The typical operating temperature of HT-PEM is around $160-180^{\circ} \mathrm{C}$ that results in improved electrochemical kinetics for electrode reaction in comparison to the low temperature (LT) PEM FC. Other advantages of HT-PEM related to the enhanced operating temperature are higher tolerance to impurities like carbon monoxide [7, 8] and simpler water management [1]. Zhang et al. [9] investigated the dependence of the FC performance on temperature. They found that in the range of $120-180{ }^{\circ} \mathrm{C}$, the enhanced temperature decreases the membrane resistance leading to higher cell power density [10].

However, for this type of FC there are some challenges which need to be solved, for example increased degradation rate at more demanding operating temperature [1113]. Possible stressors for the operation of a HT-PEM FC are mass transfer limitation due to the presence of phosphoric acid in the catalyst layer [14, 15], electrochemical cycling, the start/stop procedure, and fuel starvation [16].

Fuel starvation, which refers to hydrogen undersupply $\left(\mathrm{H}_{2}\right.$ starvation), occurs during startup and shutdown due to the rapid load variation or as a consequence of inhomogeneous $\mathrm{H}_{2}$ distribution in a single cell or between assemblies of cells [17]. In addition, an uneven distribution of phosphoric acid in the the HT-PEM FC [18, 19], during MEA manufacturing and/or the activation process, can also flood the catalyst and results in local hydrogen undersupply [20].

During $\mathrm{H}_{2}$ starvation, the local depletion of $\mathrm{H}_{2}$ leads to an inhomogeneous current density distribution over the active surface area of the MEA [17], which can either 
lead to active points $\left(\mathrm{P}_{\mathrm{ac}}\right)$ being sufficiently supplied with $\mathrm{H}_{2}$ or insufficiently supplied parts of surface area defined as inactive points. The non-sufficient or inactive areas may accelerate fuel cell degradation.

Previously, the behavior under $\mathrm{H}_{2}$ starvation was investigated for LT-PEM FCs and phosphoric acid fuel cells (PAFC). For example, Zhang et al. [21] investigated air and $\mathrm{H}_{2}$ starvation for LT-PEM FC under controlled current and voltage modifications. They observed that current density and temperature distribution were inhomogeneous across the FC depending on the location along the flow channel. Song et al. investigated an influence of anode starvation on PAFC. The experimental results show a $5 \mathrm{mV}$ loss in cell voltage after $\mathrm{H}_{2}$ starvation [22].

Zhou et. al. [17] studied the effect of $\mathrm{H}_{2}$ starvation in HT-PEM FC on voltage and local current density measured simultaneously under different stoichiometries $\left(\lambda_{A}<\right.$ 1.0) and at different current loads. They observed that the current density under $\mathrm{H}_{2}$ starvation is highest in the upstream (inlet) regions, decreasing along the flow channel direction and lowest in downstream (outlet) regions due to high mass transfer resistances.

The consequences of $\mathrm{H}_{2}$ starvation are reported differently. Liang at al. [23] observed that under $\mathrm{H}_{2}$ starvation water electrolysis and carbon corrosion take place at the anode side of the FC. Carbon corrosion may lead to the irreversible loss of the electrochemical catalyst surface area (ECSA) [24]. Those undesirable reactions could have an influence on changes inside the MEA, e.g. in thickness and / or on the morphology [25, 26]. Therefore, to increase the lifetime of HT-PEM FCs the effects of $\mathrm{H}_{2}$ starvation need to be investigated in more detail.

In this work we present $\mathrm{H}_{2}$ starvation / regeneration cycles up to 550 minutes for 2 identical HT-PEM FC MEAs under operation. The regeneration step allows the evaluation of (ir)reversible degradation after each starvation step. To the best of our knowledge such a repeated combination of starvation / regeneration procedures has not yet been reported. The cyclicity of experiments was used to study the long term durability of the HT-PEM FC. Both, voltage and current density mapping were measured each minute simultaneously, allowing the evaluation of changes in FCs as a function of time and the optimization of the operational strategies to prevent FC lifetime reduction.

\section{Basics}

A FC produces electricity at the fixed current density $i\left(A \cdot \mathrm{cm}^{-2}\right)$. When the current is applied the electrochemical reaction leads to the depletion of the reactants at the catalyst layer. Then i can be calculated using the following equation

$\mathrm{i}=\mathrm{nF} \dot{\mathrm{m}} / \mathrm{A}_{\mathrm{ac}}$

whereas $\mathrm{n}$ is the number of electrons transferred per mole of reactant consumed, $\mathrm{F}$ is Faraday constant, $\mathrm{s} \cdot \mathrm{A} \cdot \mathrm{mol}^{-1}, \dot{\mathrm{m}}$ is the rate of mass transfer by diffusion of reactants to the catalyst layer, $\mathrm{mol} \cdot \mathrm{s}^{-1}$ and $A_{\mathrm{ac}}$ is active area, $\mathrm{cm}^{2}$. The operating current (I) can be then calculated by: 
117 Under $\mathrm{H}_{2}$ starvation, $\mathrm{A}_{\mathrm{ac}}$ will be reduced due to unsufficient gas flow. Meanwhile, under the $\mathrm{H}_{2}$ undersupply, the reduction of $\mathrm{A}_{\mathrm{ac}}$ or respectively the inhomogenous current density distribution can be measured with local current densities $\left(\mathrm{I}_{1}\right)$, for example if the $A_{a c}$ is divided over 100 points of the flow field. In case of a full homogeneity the current density is equal at all the 100 points and shall be higher than $0.04 \mathrm{~A}^{\text {ppoint }}{ }^{-1}$. The explanation of the chosen $0.04 \mathrm{~A} \cdot$ point $^{-1}$ current density will follow in chapter 3.

In order to evaluate inhomogenous current density distribution, the 100 points can be divided into two categories: the active points $\left(\mathrm{P}_{\mathrm{ac}}\right)$ with a current density greater than or equal to $0.04 \mathrm{~A} \cdot$ point $^{-1}$ and the inactive points corresponding to less than 0.04 $A \cdot$ point $^{-1}$. From the sum of active points (count of $P_{a c}$ ) the active area can be calculated with with the assumption below:

$A_{a c} \propto \Sigma P_{a c}\left(\right.$ if $\left.P_{a c} \geq 0.04 A\right) ;$

The gas flow through the bipolar plate channels can be characterized by the gas partial pressure gradient which is strongly determined by the flow field design. If continuous gas consumption is assumed, there is a common depletion gradient of reactor gas partial pressure from inlet to the outlet [27, 28] (Fig. 1a, white arrow). There is almost no difference in the partial pressure of neighboring channels (e.g. 1.5., Fig. 1a, b) compared to the adjacent channels (with opposite flow directions) along the flow channel (e.g. 1. and 6., Fig. 1b), which is due to the fuel consumption in the cell reaction. The partical pressure difference between two channels forces $\mathrm{H}_{2}$ transport through the gas diffusion layer under the rib, which leads to an improvement of the local current density.

The decrease in $\mathrm{H}_{2}$ partial pressure at the catalyst surface may increase anodic mass transport resistance, leading to an increase in the anode overpotential [17]. Therefore $\mathrm{H}_{2}$ starvation typically results in a significant drop in cell voltage. 


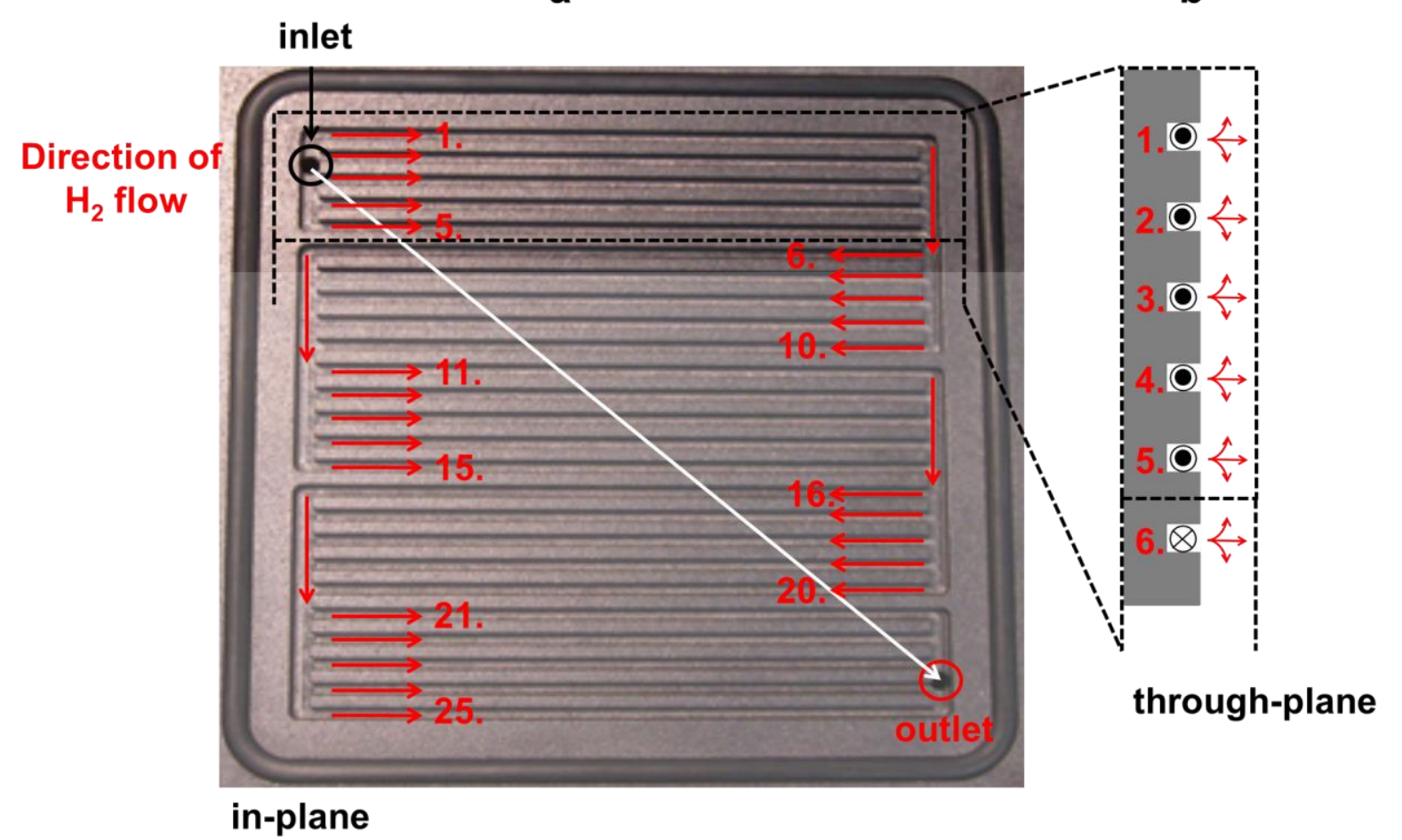

Fig. 1: a) In-plane view of serpentine flow field and b) schematic representation of the gas transport in serpentine flow field (through-plane view). Red arrows show the

$\mathrm{H}_{2}$ flow directions; 0 indicates the gas flow perpendicular to the paper from the bottom upwards, and $\otimes$ indicates the flow perpendicular to the paper from the bottom downwards.

\section{Experimental setup}

\subsection{Hardware setup}

In this work, three identical MEAs Dapozol® G77 (Danish Power Systems $®$ ), were chosen for testing. This type of MEA is based on a $\mathrm{PBI} / \mathrm{H}_{3} \mathrm{PO}_{4}$ membrane with an active area of $21 \mathrm{~cm}^{2}$. The membrane was placed between two gas diffusion electrodes (GDE). The assembly with a thickness of around $0.6 \mathrm{~mm}$ was inserted between two graphite flow fields with five quintuple serpentine flow channels (Fig. 1a). The MEAs were tested on a FC test station FuelCon AG (Evaluator-C 70316).

A current density and temperature distribution device $\left(\mathrm{S}^{++}\right.$Simulation Services $\AA$ ) was installed during the whole experiment on the anode side under the flow field (Fig. 2a). The shematic representation of the $\mathrm{S}^{++}$unit location under the serpentine flow field is presented in Fig. $2 b$ (overlapped view of $S^{++}$unit and the flow field; Fig. 1a). The $\mathrm{S}^{++}$ unit consists of 100 points (intercepts) and each of them provides information about local current density $\left(\mathrm{I}_{1}\right)$, which builds up a 2D distribution map of current densities. Fig. 2b and Fig. 2c present the locations and numbering principle of 100 points from $\mathrm{S}^{++}$unit at the flow field.

The flow channel from inlet to outlet can be divided into 50 sections (Fig. 2d) while each section corresponds to two points at $S^{++}$unit (e.g. i.1 and ii.1). Those 50 
sections enable gas flow from one side the other (e.g. i/ii.1 - i/ii.50). However, at the intercepts i.1 / ii.1 and i. / ii.50 where MEA was fixed to the $S^{++}$device, there is always zero current density, therefore, those values were neglected for further calculations. The result of current density mapping will be visualized as a segmented surface, each segment consists of four adjacent points of about $0.25 \mathrm{~cm}^{2}$ size.

Beside the 2D distribution map over the MEA, the current density was also plotted as an "unfolded" view along the flow direction from inlet to outlet, as normal in simulation work (Fig. 2e) [29]. Since each section along the flow direction corresponds to two points of the $\mathrm{S}^{++}$unit, there are two current density values at each section of the unfolded view.

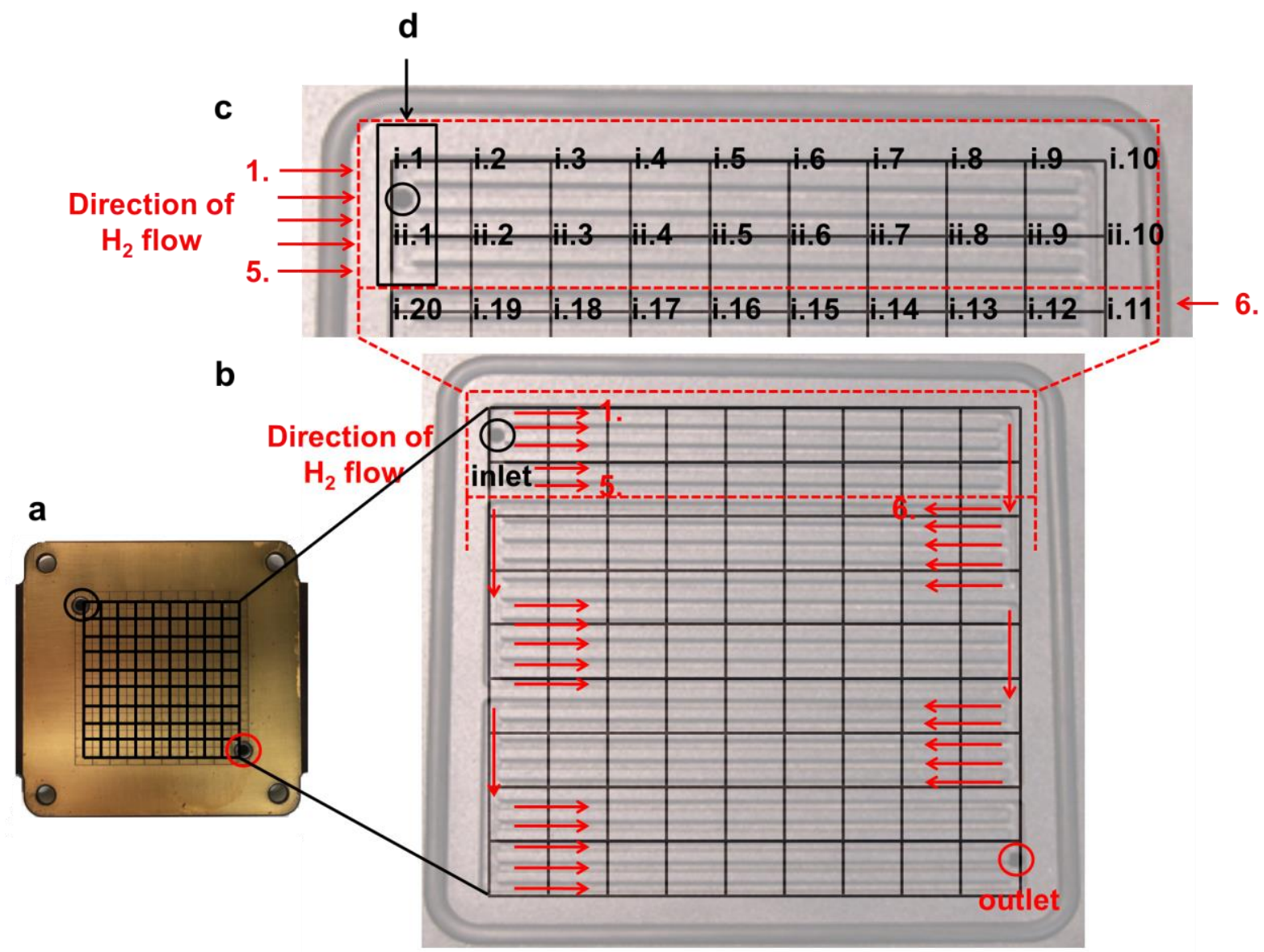

e

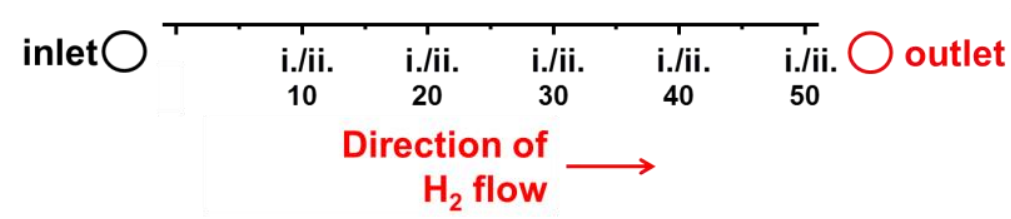

Fig. 2: a) Current density distribution device $\left(S^{++}\right.$unit), b) serpentine flow field schematically overlapped with the $S^{++}$unit (location of $S^{++}$points (intercepts) "folded" view, c) zoom into intercept locations from i.1 to i.20, d) exemplary section at the flow channel (points: i.1 and ii.1) and e) "unfolded" view of the sections $\left(\mathrm{S}^{++}\right.$ serpentine pattern) at the flow channel (from inlet to outlet).

Micro-computed tomography $(\mu-C T)$ allows a non-destructive view into HT-PEM FC components and was conducted to measure the thicknesses of different layers of the 
MEA. Measurements were carried out with the microcomputed X-ray tomography system (Skyscan 1172 Desktop-Micro-CT, Bruker, Belgium). The samples were prepared with a hole-puncher $(\varnothing 4 \mathrm{~mm})$. Those samples were cut from two different locations on the MEAs (1-near inlet; 2-near outlet) (Fig. 3). In order to receive comparable results the geometrical resolution of each measurement was held constant by $1.23 \mu \mathrm{m} \cdot \mathrm{px}^{-1}$. The thickness of defined layers, such as cathode catalyst layer and anode catalyst layer of the investigated location was measured with the help of the software Dataviewer (Fig. 3). The values for thicknesses were calculated by averaging ten values of five sagittal or coronal 2D-images [30]. The settings used for these investigations are summarized and shown in Table 1 [25].

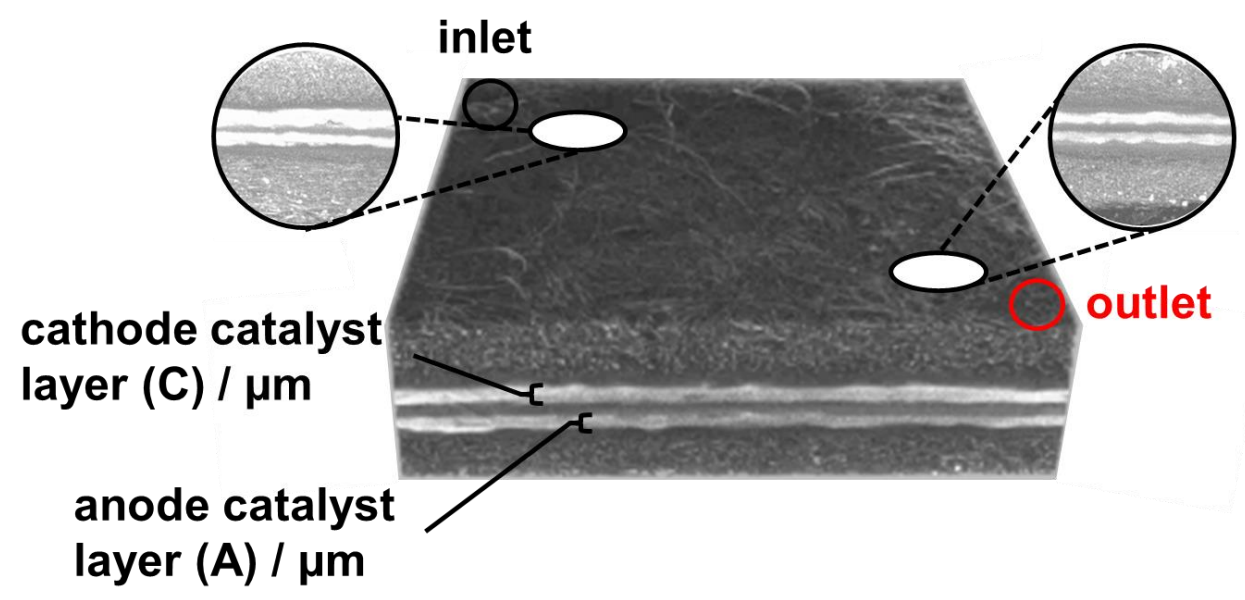

Fig. 3: Schematic presentation of an exemplary 3D $\mu-C T$ image.

Tab. 1: Operational settings in $\mu-C T$.

\begin{tabular}{|c|c|c|}
\hline Parameter & Value & Unit \\
\hline Acceleration voltage & $78-82$ & $\mathrm{kV}$ \\
\hline Source current & $96-102$ & $\mu \mathrm{A}$ \\
\hline Sample size $\varnothing$ & $4-5$ & $\mathrm{~mm}$ \\
\hline Rotation step & 0.2 & $\circ$ \\
\hline Random movement & 10 & - \\
\hline Averaging & 4 & - \\
\hline Optical resolution & 1.23 & $\mu \mathrm{m} \cdot \mathrm{px}^{-1}$ \\
\hline Duration & $140-180$ & $\mathrm{~min}$ \\
\hline
\end{tabular}

\subsection{Experimental procedure}

Prior to the electrochemical experiments the assembled HT-PEM FC was activated [31] by heating up the cell under $\mathrm{N}_{2}$ supply to a temperature of $120^{\circ} \mathrm{C}$. Subsequently reactant gases were fed: hydrogen with a stoichiometric factor of 1.5 for the anode 
$\left(\lambda_{A}=1.5\right)$ as fuel, and oxygen with a stoichiometric factor of 9.5 for the cathode $\left(\lambda_{C}=\right.$ $9.5)$ as oxidant while the temperature was increased to $160^{\circ} \mathrm{C}$. Shortly after, the load current was increased stepwise up to $6.35 \mathrm{~A}$. The stoichiometry factor is based on the ratio between the available gas at the inlet and the required gas necessary for the reaction [32].

The intended oversupply of oxygen avoids any influences from the cathodic side of the FC and for clear separation of degradation phenomena on the anode side. The following activation procedure was conducted for each cell. From the time when stable operation was reached $\left(0.3 \mathrm{~A} / \mathrm{cm}^{2}\right.$ with $\lambda_{A}=1.5$ and $\left.\lambda_{C}=9.5\right)$, such condition was kept constant for $168 \mathrm{~h}$ in order to reach constant voltage.

Starvation / regeneration cycles were repeated for up to 550 minutes. Each cycle consisted of a starvation process with $\lambda_{A}=1.0$ at $6.35 \mathrm{~A}$ (equals $0.3 \mathrm{~A} / \mathrm{cm}^{2}$ ) and kept at a value of 9.5 in all conditions. The load of $6.35 \mathrm{~A}$ was chosen for the starvation step, representing a standard value for typical FC operation [33]. After that the $\mathrm{FC}$ was held under $0.4 \mathrm{~A} / \mathrm{cm}^{2}$ for 20 minutes for regeneration to assure full $\mathrm{FC}$ recovery after starvation.

\section{Results and discussions}

Previous experiments were performed under different anode stoichiometries: $\lambda_{A}=$ $0.9, \lambda_{A}=1.0$ and $\lambda_{A}=1.1$. At $\lambda_{A}=0.9$ the FC immediately lost performance and the gas supply was automatically turned off due to test bench security thresholds, while at $\lambda_{A}=1.1$ the FC ran stable. At $\lambda_{A}=1.0$ the cell operated for several minutes, followed by a sharp voltage drop to test bench safety limits and the system was turned off. Hence, for the detailed study of starvation processes the stoichiometry $\lambda_{A}$ $=1.0$ was chosen.

As shown in Fig. 4a the starvation steps repeatedly induced a significant voltage drop. However, the immediate response during regeneration was a stable and constant voltage at $0.6 \mathrm{~V}$. This could indicate that, if degradation by $\mathrm{H}_{2}$ starvation occurred during the first starvation step it would have probably been insignificant.

In particular, the first starvation step lasted ca. 25-26 minutes for both DPS (Fig. 4b), and as expected, at $\lambda_{\mathrm{A}}=1.0$ voltage starts to drop from ca. $0.6 \mathrm{~V}$ after around 20 minutes down to minimal safety limits (ca. $0.1 \mathrm{~V}$ ). Despite the voltage drop, the sum of local current densities of 100 points from the $S^{++}$unit $\left(\Sigma l_{1}\right)$ yielded $6.35 \pm 0.30 \mathrm{~A}$ throughout the whole starvation step (as well as $8.46 \pm 0.45 \mathrm{~A}$ during regeneration; Fig. 4c). The visible fluctuations in $\Sigma I_{1}$ in Fig. 4c likely occured due to single point current density fluctuations.

Figure 4d shows the current distribution at minutes 1 and 26 in the first starvation step for DPS-1. At minute 1 the current is well distributed all over the $A_{a c}$. Except for the few points directly at the inlet and outlet the current is $0.07 \mathrm{~A} \cdot$ point $^{-1}(0.639 \mathrm{~V})$. However, at minute 26 there is a clear deviation in current distribution, with points near the inlet reaching about $0.3 \mathrm{~A} \cdot$ current $^{-1}$ and points near the outlet decreasing to about $0.01 \mathrm{~A} \cdot$ point $^{-1}$. The $\mathrm{H}_{2}$ concentration is higher near the inlet than near the outlet, which corresponds to the common gradient within the serpentine flow field (Fig. 1, white arrow) [27]. 


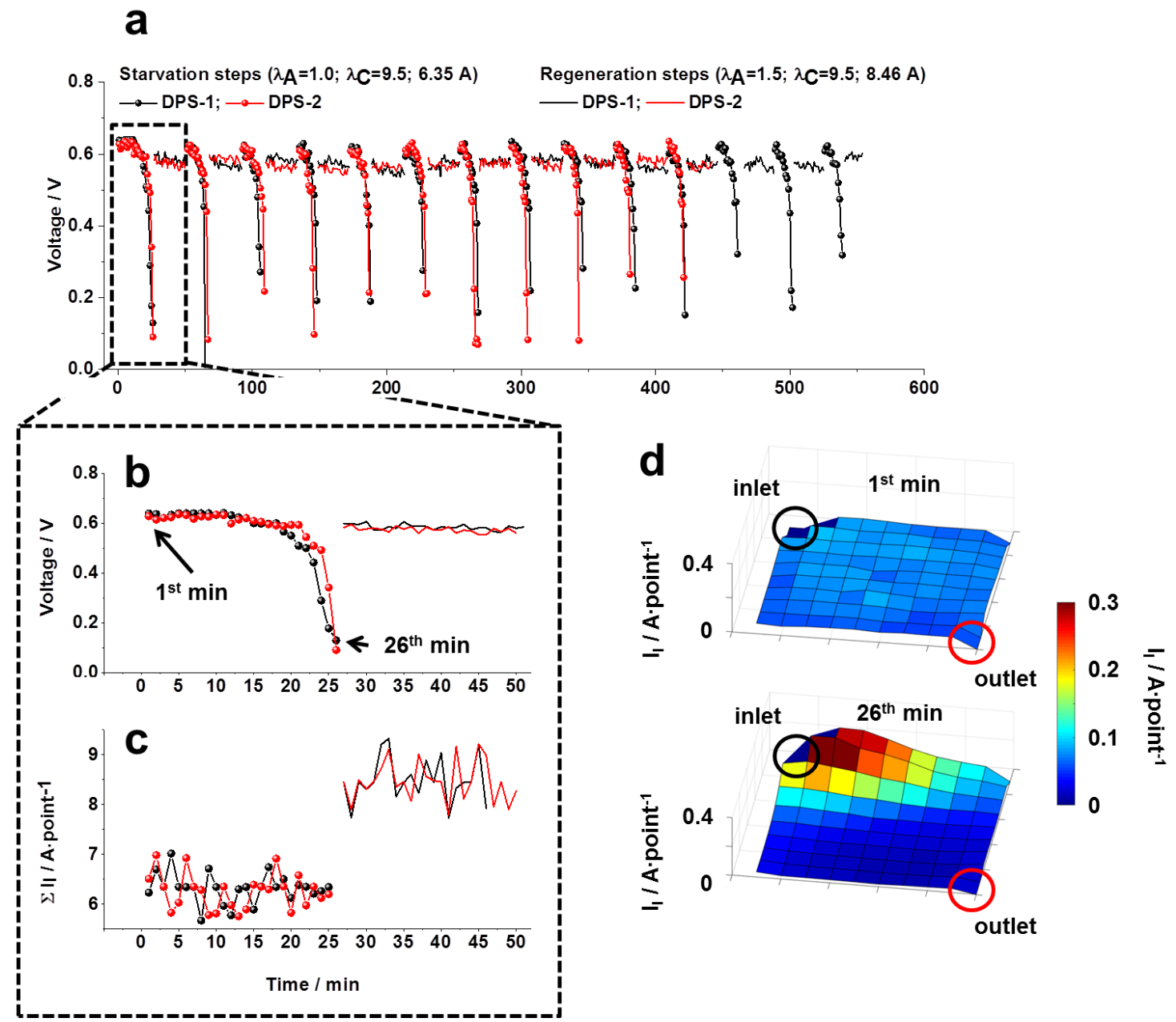

Fig. 4: a) Cell voltage of DPS-1 and 2 during ca. 550 min operation, b) zoom of voltage and c) sum of local current densities of 100 points from the $\mathrm{S}^{++}$unit for starvation / regeneration step $1 \mathrm{vs}$. time as well as d) 3D local current density distribution for minutes 1 and 26 in DPS-1 during starvation step 1.

For a better differentiation of the processes near the outlet the density distribution is shown as a 2D map in more detail for the lower current ranges for the minutes 1,11 and 26 (Fig. 5a) and as current density values extracted from every point of the map in the "unfolded" view (Fig. 5b). At minute 1 the current is around $0.07 \mathrm{~A} \mathrm{point}^{-1}$, which indicates a balanced operation and distribution over the whole area. Hence, during the first 10 minutes the system operates stable only with marginal differences in voltage and local current densities. However, at minute 11 the intercepts from i./ii.41 to i./ii.50 close to the outlet operated with a current density $\leq 0.04$ A.point ${ }^{-1}$ while at minute 26 more than half of $A_{a c}$ operated below $0.04 \mathrm{~A} \mathrm{point}^{-1}$ (Fig. 5). Next to the observed drop to $0.01 \mathrm{~A} \cdot$ point $^{-1}$ at minute 26 the current densities near the inlet significantly increase up to $0.3 \mathrm{~A} \cdot$ point $^{-1}$ (Fig. 4c). However, the sum of local current densities yielded the nominal current $(6.35 \mathrm{~A})$ such as in minutes 1 and 11.

To compensate for the two times lower current and to reach the nominal current in total $(6.35 \mathrm{~A})$ the remaining intercepts (80 points) increased their current densities by more than $0.07 \mathrm{~A} \cdot$ point $^{-1}$. Therefore, the minute 11 is taken as the onset of deviation from the balanced current density distribution during starvation. The current density 
of $0.04 \mathrm{~A} \cdot$ point $^{-1}$ indicates the instability of $A_{a c}$ at minute 11 . However, at that time the respective voltage value is still the same as in minute 1 (Fig. $4 \mathrm{a}$ ).

The outliers (current density decrease) at the points i./ii.10 and i./ii.11 of the gas flow from inlet to outlet (Fig. 5) can be explained with the channel geometry of the flow field, since at those points the $\mathrm{H}_{2}$ gas flow is constricted (Fig. 1a). The outlier of gas flow from inlet to outlet (e.g. intercept i.25; Fig. 5) at which current density repeatedly increased after the decrease in previous intercepts can be due to an in-plane crossover effect passing over the geometry of flow channels [34].

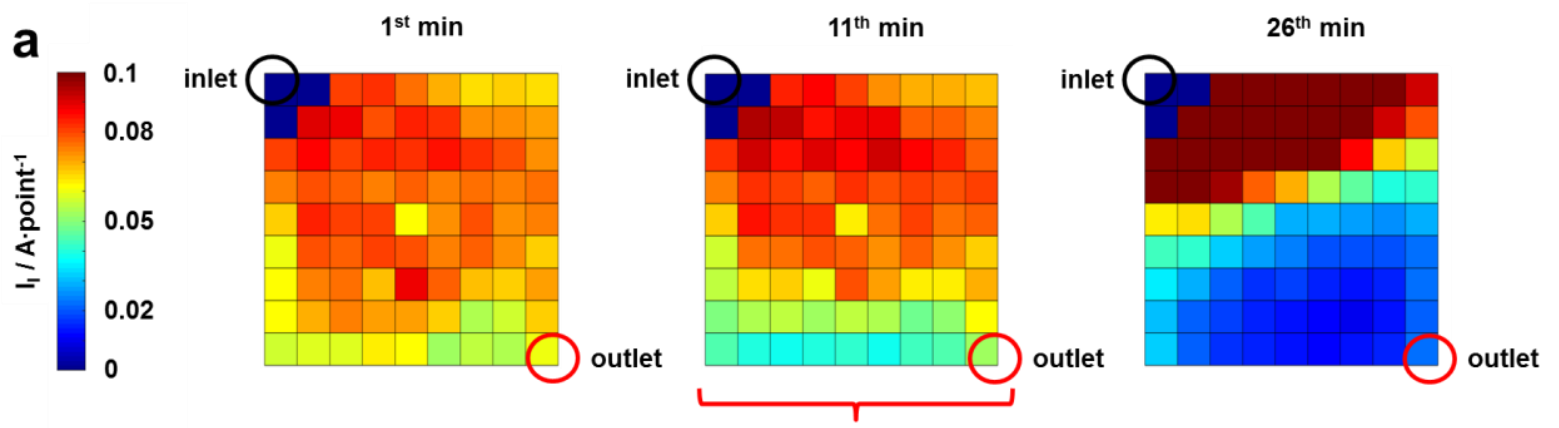

b

Fig. 5: a) 2D current density distribution maps during starvation step 1 at minutes 1 , 11 and 26, b) Unfolded view of the current densities (A point ${ }^{-1}$ ) for minutes 1,11 and 26 extracted from the 2D maps (Fig. 5), red bracket points to current decrease at minute 11.

The number of points, where the local current density is $>0.04 \mathrm{~A} \cdot$ point $^{-1}$ represents an area with sufficient $H_{2}$ supply $\left(P_{a c}\right)$, which balance $A_{a c}$ to the actual operational current. The residual points $\left(<0.04 \mathrm{~A}\right.$.point $\left.{ }^{-1}\right)$ have insufficient $\mathrm{H}_{2}$ supply, and the partial pressure balance of the system is disturbed. In order to balance the low $\mathrm{H}_{2}$ partial pressure against ambient pressure, undesirable air may back-feed into the anode side of the assembly (air front) from the open outlet, which may further expand to about i./ii.20 ${ }^{\text {th }}$ (Fig. 4a; $5 \mathrm{~b}$ ). As soon as an $\mathrm{H}_{2}$ and air front builds up on the anode side, the MEA acts not only as the fuel cell (hydrogen oxidation reaction (HOR) anode side / oxygen reduction reaction (ORR) - cathode side), but also as the galvanic cell (HOR and oxygen evolution reaction (OER) -anode side / ORR cathode side) [35].

The air - filled part of the anode side shifts the potential in the adjacent cathode electrode (ca. $1.5 \mathrm{~V}$ vs. reversible hydrogen electrode $(\mathrm{RHE})$ ). Such potential is high enough to start OER and lead to carbon oxidation currents. The electrochemical 
305 oxidation of the carbon catalyst support (Eq. 3) is thermodynamically achievable at 306 potential $>0.2 \mathrm{~V}_{\mathrm{RHE}}$.

$307 \mathrm{C}+2 \mathrm{H}_{2} \mathrm{O} \rightarrow \mathrm{CO}_{2}+4 e^{-}+4 \mathrm{H}^{+}$

308 The consequence of the carbon oxidation of the carbon electrodes is cathode 309 thinning i.e. loss of void volume within the cathode catalyst layer and a concomitant 310 decrease in cathode layer thickness as reported in [36].

311 The anode catalyst layer may also suffer from air fronts on the anode side. Engl et al. 312 [37] reported carbon corrosion in HT PEM FC along with a loss of a $\mathrm{Pt}$ 313 electrochemical surface area (ECSA). The authors attributed this to the difference of 314 the anode potential due to change of MEA operation between fuel cell and the 315 galvanic cell. Similar findings of anode catalyst layer local thinning were also 316 observed by our group [38].

317 As a consequence, both anode and cathode sides can undergo degradation due to 318 anode starvation. 


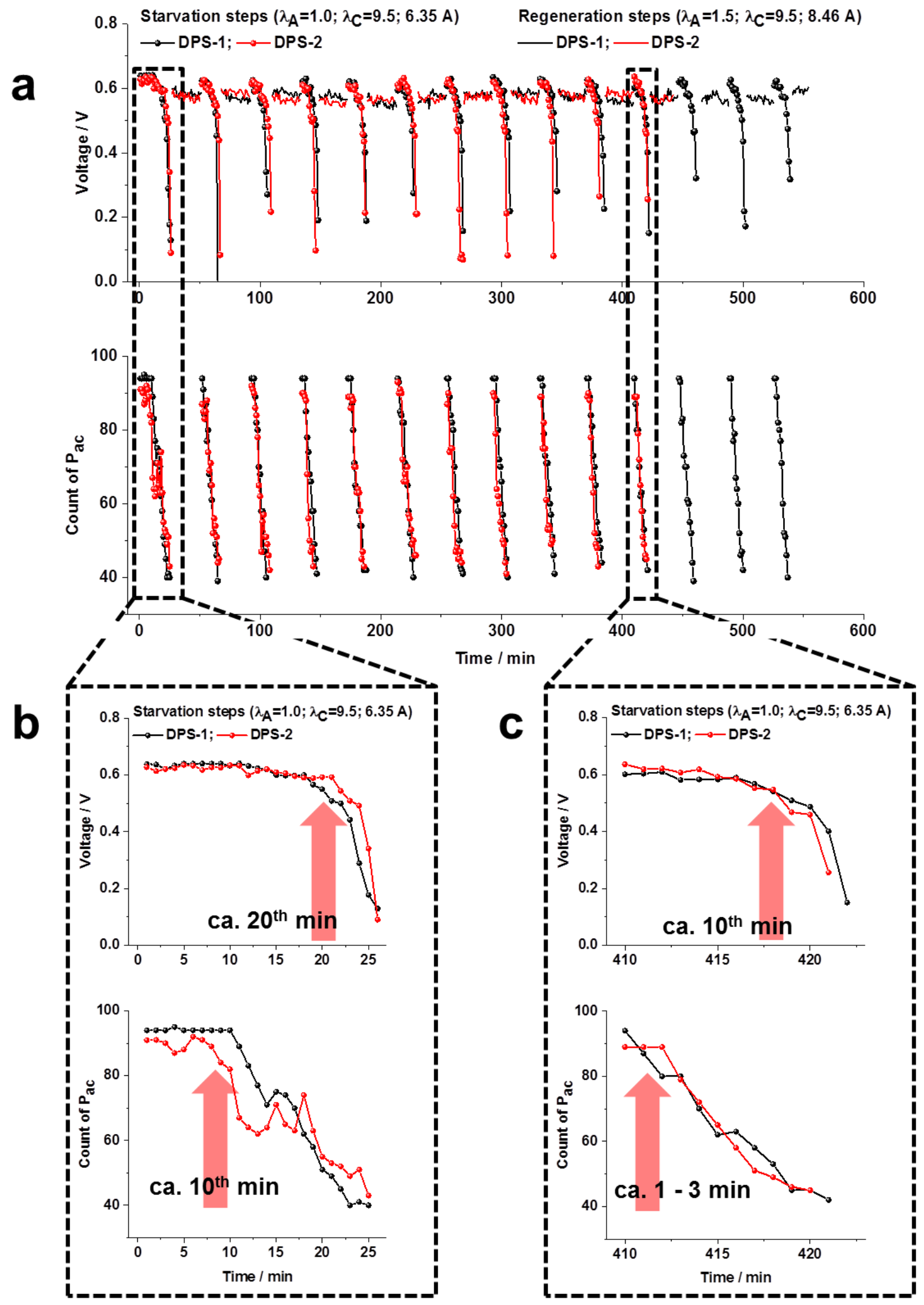

Fig. 6: a) Voltage behavior and $P_{a c}$ for the 14 and 11 starvation steps and voltage behavior during regeneration step for DPS-1 and DPS-2 respectively, vs. time, b) zoom into the first starvation step of DPS-1 and DPS-2 and c) zoom into the $11^{\text {th }}$ starvation step of DPS-1 and DPS-2. 
Accordingly, the $A_{a c}$ is divided into sufficient and insufficient $\mathrm{H}_{2}$ supply, and 0.04 A.point ${ }^{-1}$ is taken as the threshold value. The number of points with sufficient $\mathrm{H}_{2}$ supply $\left(P_{\mathrm{ac}}\right)$ was determined for both DPS-1 and 2 (Fig. 6a) and, like the voltage drop, highly reproducible and essentially the same for both MEAs. Both DPS- 1 and DPS-2 consist at the start of each starvation of ca. 95 sufficiently supplied points (ca. $21 \mathrm{~cm}^{2}$ ), the number of which decreases during the starvation to ca. 40 points. Hence, in the last minute of starvation the critical surface area is ca. $9 \mathrm{~cm}^{2}$. However, if one compares the first starvation of DPS-1 and DPS-2 and the rest of starvation steps, the time until voltage drops to below $0.2 \mathrm{~V}$ is in the first starvation period for both MEAs (26 min; determined by safety shut-down) about twice as long as the later starvation steps (10-15 min). The closer look at the first (Fig. 6b) and last starvation (Fig. 6c) of both DPS-1 and DPS-2 shows that the significant voltage drop starts at the first starvation step after $20 \mathrm{~min}$ and for the last starvation step after $10 \mathrm{~min}$. Further, the decrease in $\mathrm{P}_{\mathrm{ac}}$ starts after ca. 10 minutes during the first starvation step and after 1-3 minutes during the last starvation step for both DPS-1 and DPS-2. This shows that the deviation of the current distribution starts earlier than the significant drop in voltage during each starvation step. Therefore, the current distribution analysis is more sensitive to the changes occurring in MEAs and suitable for the early prediction of $\mathrm{H}_{2}$ starvation.

The identical response in voltage and $\mathrm{P}_{\mathrm{ac}}$ during $\mathrm{H}_{2}$ starvation as well as the identical voltage response during the regeneration steps allow a first assessment of degradation effects. Since all regeneration steps showed a stable voltage at ca. $0.6 \mathrm{~V}$ (Fig. 6a) it can be assumed that no severe degradation took place during the starvation / regeneration steps. However, according to published experimental results possible degradation mechanisms caused by $\mathrm{H}_{2}$ starvation may consist of (i) backfeeding processes and/or (ii) water electrolysis with subsequent corrosion processes at the anode side [37]. Those may lead to irreversible changes in MEAs, such as layer thickness and morphology [36, 39]. Therefore, in order to evaluate the impact of starvation on the catalyst layers $\mu$-CT measurements were conducted for both anode and cathode sides, for the areas located at the inlet and the outlet. Table 2 shows the comparison of catalysts layer thicknesses obtained for the fresh MEA from the same batch (DPS-0, not been assembled in the FC test station) with those of DPS-1.

As shown in Table 2 the thicknesses of both cathode and anode catalyst layers were reduced by about $30 \%(8-11 \mu \mathrm{m})$ compared to a fresh MEA. Apparently, $\mathrm{H}_{2}$ starvation has a thinning effect on the layers of DPS-1. The anode catalyst layer thickness is slightly lower than the cathode catalyst layer at both inlet and outlet after $\mathrm{H}_{2}$ starvation. However, there is almost no thickness difference between inlet and outlet of the same catalyst layers. This could be due to the fact that the total time under starvation conditions (about $550 \mathrm{~min}$ ) was too short to have significant influence on the thickness of catalyst layer at two different places of the MEA surface. It can be concluded that after the 14 starvation steps the overall thickness of the anode and cathode catalyst layers are only slightly affected. Even if the layer thickness appears to be reduced (Table 2) the performance of the DPS remained unchanged (Figs. 4-6). Results on starvation / regeneration experiments extending the number of cycles to further days of measurement (DPS-2) will be published soon in a separate paper. 
Tab. 2: Catalyst layer thicknesses as well as $\mu-C T$ images showing through-plane morphology of a fresh MEA (DPS-0) and the MEA of DPS-1 after operation. Mean values of layer thicknesses are calculated from 10 data points with single standard deviation.

\begin{tabular}{|c|c|c|c|}
\hline Sample & DPS-0 & \multicolumn{2}{c|}{ DPS-1 } \\
\hline Sample status & Fresh MEA & \multicolumn{2}{c|}{ Starvation / Regeneration } \\
\hline Measurement duration / min & 0 & ca. 550 & ca. 550 \\
\hline Location & & inlet & outlet \\
\hline $\begin{array}{c}\mu-\mathrm{CT} \text { image } \\
\end{array}$ & C A & C & C \\
\hline $\begin{array}{c}\text { cathode catalyst layer thickness (C) } \\
/ \mu \mathrm{m}\end{array}$ & $35.3 \pm 4.0$ & $27.2 \pm 6.2$ & $28.6 \pm 5.6$ \\
\hline $\begin{array}{c}\text { anode catalyst layer thickness (A) } \\
/ \mu \mathrm{m}\end{array}$ & $35.6 \pm 6.0$ & $24.5 \pm 4.0$ & $24.3 \pm 4.5$ \\
\hline
\end{tabular}

\section{Conclusions}

In this work, two identical MEAs from a DPS of a HT-PEM FC were cycled under anode starvation / regeneration conditions for up to $550 \mathrm{~min}$, which included up to 14 starvation steps. The results show that during starvation, cell voltage and current density distribution over the active area of the MEAs significantly differed from nominal conditions. The significant drop in cell voltage from 0.6 to $0.1 \mathrm{~V}$ occured after ca. 20 minutes for the first starvation step, and after 10 minutes for all subsequent starvation steps. Compared to that the voltage response of both MEAs is immediate, stable and constant at $0.6 \mathrm{~V}$ during all subsequent regeneration steps.

Further, during each starvation, the local current density reached up to $0.3 \mathrm{~A} \cdot$ point $^{-1}$ at the area near the gas inlet $\left(9 \mathrm{~cm}^{2}\right)$ while near the outlet it drops to $0.01 \mathrm{~A} \cdot \mathrm{point}^{-1}$. The deviation from a balanced current density distribution occurred after 10 minutes for the first starvation step, and after ca. 2 minutes for the subsequent starvation steps. Hence, compared to the voltage drop the deviation from a balanced current density distribution always starts earlier. This indicates that the local current density distribution is more sensitive to local changes in the MEA than the cell voltage drop, which is an averaged measurement. Such conclusion is applicable for various types of MEAs with different active areas. This finding may help to prevent undesirable influences of the starvation process. 


\section{Acknowledgements}

The authors would like to thank the Federal Ministry of Economic Affairs and Energy (Project QUALIFIX). Special thanks to Ralf Kraume for kind and valuable technical support as well for useful discussions.

\section{References}

[1] Wang Y, Sauer DU, Koehne S, Ersoez A. Dynamic modeling of high temperature PEM fuel cell start-up process. Int J Hydrogen Energy 2014;39:19067. doi: https://doi.org/10.1016/j.ijhydene.2014.09.095

[2] Andreasen SJ, Ashworth L, Sahlin S, Becker Jensen H-C, Kær SK. Test of hybrid power system for electrical vehicles using a lithium-ion battery pack and a reformed methanol fuel cell range extender. Int J Hydrogen Energy 2014;39:1856. doi: https://doi.org/10.1016/j.ijhydene.2013.11.068

[3] Martin S, Wörner A. On-board reforming of biodiesel and bioethanol for high temperature PEM fuel cells: Comparison of autothermal reforming and steam reforming. J Power Sources 2011;196:3163.

https://doi.org/10.1016/j.jpowsour.2010.11.100

[4] Taccani R, Chinese T, Zuliani N. Performance analysis of a micro CHP system based on high temperature PEM fuel cells subjected to degradation. Energy Procedia 2017;126:421. doi: https://doi.org/10.1016/j.egypro.2017.08.198

[5] Zhang C, Yu T, Yi J, Liu Z, Raj KAR, Xia L, et al. Investigation of heating and cooling in a stand-alone high temperature PEM fuel cell system. Energy Convers Manage 2016;129:36. https://doi.org/10.1016/j.enconman.2016.10.008

[6] Arsalis A, Nielsen MP, Kær SK. Modeling and off-design performance of a 1 kWe HT-PEMFC (high temperature-proton exchange membrane fuel cell)-based residential micro-CHP (combined-heat-and-power) system for Danish single-family households. Energy 2011;36:993. https://doi.org/10.1016/j.jhydene.2011.01.121

[7] Weiß A, Schindler S, Galbiati S, Danzer MA, Zeis R. Distribution of Relaxation Times Analysis of High-Temperature PEM Fuel Cell Impedance Spectra. Electrochim Acta 2017;230:391. https://doi.org/10.1016/j.electacta.2017.02.011

[8] Li Q, He R, Jensen JO, Bjerrum NJ. PBI-based polymer membranes for high temperature fuel cells - preparation, characterization and fuel cell demonstration. Fuel Cells (Weinheim, Germany) 2004;4:147. https://doi.org/10.1002/fuce.200400020

[9] Zhang J, Tang Y, Song C, Zhang J. Polybenzimidazole-membrane-based PEM fuel cell in the temperature range of $120-200^{\circ} \mathrm{C}$. J Power Sources 2007;172:163. doi: 10.1016/j.jpowsour.2007.07.047

[10] Ma Y-L, Wainright JS, Litt MH, Savinell RF. Conductivity of PBI Membranes for High-Temperature Polymer Electrolyte Fuel Cells. J Electrochem Soc 2004;151:A8. doi: $10.1149 / 1.1630037$ 
[11] Park J, Min K. A quasi-three-dimensional non-isothermal dynamic model of a high-temperature proton exchange membrane fuel cell. J Power Sources 2012;216:152. https://doi.org/10.1016/j.jpowsour.2012.05.054

[12] Lebæk J, Ali ST, Møller P, Mathiasen C, Nielsen LP, Kær SK. Quantification of in situ temperature measurements on a PBI-based high temperature PEMFC unit cell. Int J Hydrogen Energy 2010;35:9943.

https://doi.org/10.1016/j.ijhydene.2009.10.002

[13] Weng F-b, Cheng C-K, Lee C-Y, Chang C-P. Analysis of thermal balance in high-temperature proton exchange membrane fuel cells with short stacks via in situ monitoring with a flexible micro sensor. Int J Hydrogen Energy 2014;39:13681. https://doi.org/10.1016/j.ijhydene.2014.04.026

[14] Mamlouk M, Scott K. The effect of electrode parameters on performance of a phosphoric acid-doped PBI membrane fuel cell. Int J Hydrogen Energy 2010;35:784. doi: https://doi.org/10.1016/j.jijhydene.2009.11.027

[15] Halter J, Marone F, Schmidt TJ, Büchi FN. Breaking through the Cracks: On the Mechanism of Phosphoric Acid Migration in High Temperature Polymer Electrolyte Fuel Cells. J Electrochem Soc 2018;165:F1176. doi: 10.1149/2.0501814jes

[16] Araya SS. High Temperature PEM Fuel Cells: Degradation \& Durability. Department of Energy Technology. Aalborg: Aalborg Univeristy; 2012, p. 147. Ph.D. thesis.

[17] Zhou F, Andreasen SJ, Kær SK. Experimental study of cell reversal of a high temperature polymer electrolyte membrane fuel cell caused by $\mathrm{H} 2$ starvation. Int $\mathrm{J}$ Hydrogen Energy 2015;40:6672. http://dx.doi.org/10.1016/j.jhydene.2015.03.148

[18] Kannan A, Li Q, Cleemann LN, Jensen JO. Acid Distribution and Durability of HT-PEM Fuel Cells with Different Electrode Supports. Fuel Cells 2018;18:103. doi:10.1002/fuce.201700181

[19] Becker H, Reimer U, Aili D, Cleemann LN, Jensen JO, Lehnert W, et al. Determination of Anion Transference Number and Phosphoric Acid Diffusion Coefficient in High Temperature Polymer Electrolyte Membranes. J Electrochem Soc 2018;165:F863. doi: 10.1149/2.1201810jes

[20] Orfanidi A, Daletou MK, Sygellou L, Neophytides SG. The role of phosphoric acid in the anodic electrocatalytic layer in high temperature PEM fuel cells. J Appl Electrochem 2013;43:1101. doi: 10.1007/s10800-013-0626-2

[21] Zhang G, Shen S, Guo L, Liu H. Dynamic characteristics of local current densities and temperatures in proton exchange membrane fuel cells during reactant starvations. Int J Hydrogen Energy 2012;37:1884.

https://doi.org/10.1016/j.ijhydene.2011.04.120 
[22] Song R-H, Kim C-S, Shin DR. Effects of flow rate and starvation of reactant gases on the performance of phosphoric acid fuel cells. J Power Sources 2000;86:289. https://doi.org/10.1016/S0378-7753(99)00450-4

[23] Liang D, Shen Q, Hou M, Shao Z, Yi B. Study of the cell reversal process of large area proton exchange membrane fuel cells under fuel starvation. J Power Sources 2009;194:847. https://doi.org/10.1016/j.jpowsour.2009.06.059

[24] Kang J, Jung DW, Park S, Lee J-H, Ko J, Kim J. Accelerated test analysis of reversal potential caused by fuel starvation during PEMFCs operation. Int $\mathrm{J}$ Hydrogen Energy 2010;35:3727. https://doi.org/10.1016/j.ijhydene.2010.01.071

[25] Rastedt M, Büsselmann J, Tullius V, Wagner P, Dyck A. Rapid and Flash Tests: Indicator for Quality of HT-PEM Fuel Cells Batches? Fuel Cells 2018;18:113. doi:10.1002/fuce.201700177

[26] Yu Y, Li H, Wang H, Yuan X-Z, Wang G, Pan M. A review on performance degradation of proton exchange membrane fuel cells during startup and shutdown processes: Causes, consequences, and mitigation strategies. J Power Sources 2012;205:10. https://doi.org/10.1016/j.jpowsour.2012.01.059

[27] Sousa T, Mamlouk M, Rangel C, Scott K. Three dimensional model of a high temperature PEMFC using PBI doped phosphoric acid membranes. Study of the flow field effect on performance. Advances in Hydrogen Energy Technologies: Oportunities and Challenges in a Hydrogen Economy - 4th International Seminar. Viana do Castelo - Portugal; 2011, p. 6.

[28] Taccani R, Zuliani N. Effect of flow field design on performances of high temperature PEM fuel cells: Experimental analysis. Int J Hydrogen Energy 2011;36:10282. https://doi.org/10.1016/j.ijhydene.2010.10.026

[29] Aquino A, Heng J. Current and Temperature Distributions in a PEM Fuel Cell. Worcester Polytechnic Institute; 2017, p. 1. Bachelor thesis.

[30] Pinar FJ, Rastedt M, Pilinski N, Wagner P. Characterization of HT-PEM Membrane-Electrode-Assemblies. High Temperature Polymer Electrolyte Fuel Cells Approaches, Status and Perspectives: Springer; 2016.

[31] Tingeloef $\mathrm{T}$, Ihonen JK. A rapid break-in procedure for PBI fuel cells. Int $\mathrm{J}$ Hydrogen Energy 2009;34:6452. https://doi.org/10.1016/j.ijhydene.2009.05.003

[32] Sahlin SL, Araya SS, Andreasen SJ, Kær SK. Electrochemical Impedance Spectroscopy (EIS) Characterization of Reformate-operated High Temperature PEM Fuel Cell Stack. IJPER 2017;1:20. https://doi.org/10.22606/ijper.2017.11003

[33] Ribeirinha $P$, Abdollahzadeh $M$, Sousa JM, Boaventura M, Mendes A. Modelling of a high-temperature polymer electrolyte membrane fuel cell integrated with a methanol steam reformer cell. Appl Energ 2017;202:6.

https://doi.org/10.1016/j.apenergy.2017.05.120 
[34] Sun L, Oosthuizen PH, McAuley KB. A numerical study of channel-to-channel flow cross-over through the gas diffusion layer in a PEM-fuel-cell flow system using a serpentine channel with a trapezoidal cross-sectional shape International Journal of Thermal Sciences 2006;45:1021.

doi: https://doi.org/10.1016/j.ijthermalsci.2006.01.005

[35] Schwämmlein JN, Rheinländer PJ, Chen Y, Freyer KT, Gasteiger HA. Anode Aging during PEMFC Start-Up and Shut-Down: H2-Air Fronts vs Voltage Cycles. J Electrochem Soc 2018;165:F1312. doi: 10.1149/2.0611816jes

[36] Banas CJ, Uddin MA, Park J, Bonville LJ, Pasaogullari U. Thinning of Cathode Catalyst Layer in Polymer Electrolyte Fuel Cells Due to Foreign Cation Contamination. J Electrochem Soc 2018;165:F3015. doi: 10.1149/2.0021806jes

[37] Engl T, Gubler L, Schmidt TJ. Fuel Electrode Carbon Corrosion in High Temperature Polymer Electrolyte Fuel Cells-Crucial or Irrelevant? Energy Technology 2016;4:65. doi:10.1002/ente.201500217

[38] Pinar FJ, Rastedt M, Pilinski N, Wagner P. Effect of idling temperature on high temperature polymer electrolyte membrane fuel cell degradation under simulated start/stop cycling conditions. Int J Hydrogen Energy 2016;41:19463. http://dx.doi.org/10.1016/j.ijhydene.2016.05.091

[39] Liu H, George MG, Messerschmidt M, Zeis R, Kramer D, Scholta J, et al. Accelerated Degradation of Polymer Electrolyte Membrane Fuel Cell Gas Diffusion Layers: I. Methodology and Surface Characterization. J Electrochem Soc 2017;164:F695. doi: 10.1149/2.0071707jes 